http://jmscr.igmpublication.org/home/ ISSN (e)-2347-176x ISSN (p) 2455-0450 crossref DOI: https://dx.doi.org/10.18535/jmscr/v8i1.175

\title{
Incidence of Tuberculosis in Post Renal Transplant Patient- A Retrospective Observational Study
}

\author{
Authors \\ Thakur Karan S. ${ }^{1}$, Kenwar Deepesh ${ }^{2}$, Sharma Ashish ${ }^{3}$
}

\begin{abstract}
Patients with End stage Renal disease are the candidates undergoing renal transplant. Organ transplantation requires use of immmunosuppresants, which exposes the patients to various opportunistic infections. In countries like India where the burden of TB is already high, patients with transplant are at a very high risk to catch these infections. Thus knowledge of TB and its incidence in renal transplant patients is very important in India.

Keywords: Renal Transplant, TB-Tuberculosis, End stage renal disease.
\end{abstract}

\section{Introduction}

Chronic kidney disease is an important contributor to morbidity and mortality in India. Renal Transplant increases the survival of CKD patients, Transplant candidates requires immunosuppresants. Use of immunosuppresants leads to attack by different opportunistic infections. In developing countries like India where TB is already a big health problem, patients with transplant are at high risk to acquire this infection.

Lung is the main site of development of TB. Other sites are lymph node, peritoneum and pleura.

\section{Cases Studies}

A retrospective non-interventional observational study which was conducted in Department of Renal Transplant Surgery, PGIMER from January 2011 to $31^{\text {st }}$ May 2018. In this all Renal transplant patients diagnosed with TB post-transplant during that period were taken as the sample size.
During the study period 1568 patients underwent Renal Transplant.

\section{Sources of Data}

Departmental database maintained on Microsoft Office Access supplemented by patient OPD records, indoor case files retrieved from Medical Records Department PGIMER Chandigarh and patients interviews over telephone or in person questionnaire form.

\section{Observation and Results}

In the study 1568 patients underwent Renal Transplant between 01.01.2011 to 31.05.2018. Out of these 68 patients were diagnosed with post transplant TB. 
Year wise data recorded as in the table

\begin{tabular}{|l|c|c|c|c|c|}
\hline YEAR & $\begin{array}{c}\text { Number of } \\
\text { TB } \\
\text { patients }\end{array}$ & $\begin{array}{c}\text { Percent } \\
\text { (out of 68 } \\
\text { TB patients } \\
\text { in study) }\end{array}$ & $\begin{array}{c}\text { Number of } \\
\text { transplants in } \\
\text { the year }\end{array}$ & $\begin{array}{c}\text { Percentage } \\
\text { (in the year) }\end{array}$ & $\begin{array}{c}\text { Incidence (per year } \\
\text { per 1000 transplants) }\end{array}$ \\
\hline 2011 & 02 & 2.9 & 175 & 1.14 & 11.4 \\
\hline 2012 & 3 & 4.4 & 187 & 1.60 & 16.0 \\
\hline 2013 & 5 & 7.3 & 200 & 2.5 & 25.0 \\
\hline 2014 & 10 & 14.7 & 206 & 4.85 & 48.5 \\
\hline 2015 & 19 & 27.9 & 247 & 7.69 & 76.9 \\
\hline 2016 & 17 & 25 & 227 & 7.48 & 39.0 \\
\hline 2017 & 9 & 13.2 & 231 & 3.9 & 31.6 \\
\hline 2018 & 3 & 4.4 & 95 & 3.16 & 40.4 \\
\hline Total & 68 & 100 & 1568 & 4.34 & \\
\hline
\end{tabular}

Mean of incidence in this study was 40.4 per year per 1000 kidney transplant patients.

\section{Discussion}

Retrospective Study was conducted in PGIMER Chandigarh. Renal transplant patients are at high risk of developing clinically significant TB. Although Renal Transplant improves the quality of life in end stage renal disease patients, it's not free of risks. The requirement of usage of immunosuppressants predisposes patients to opportunistic infections. In India prevalence of TB is high in general populations. So chances of acquiring TB in patients undergoing transplant are very high, as evident from the study. TB increases both morbidity and mortality in patient undergoing transplantation. It also interferes with overall transplant acceptance.

So it becomes very necessary to study TB in renal transplant patients in our country.

\section{References}

1. Karima B, Gargah T, Abderrahim E, Abdallah TB, Kheder A. Mycobacterium tuberculosis Infection following kidney transplantation. Bio Med Research International 2013 Article ID 347103.

2. Sundaram M, Adhikay SD, John GT, Kelke NS. Tuberculosis in renal transplant recipients. Indian J Urology. 2008;24(3): 396-400.
3. Courtney MT, Daniel B, Mark, E, Kenneth LM. Kidney and pancreas transplantation, 20 th ed. Sabiston textbook of surgery: 64963.

4. Naqvi A, Rizvi A, Hussain $Z$ et al. Developing world perspective of post transplant tuberculosis: morbidity, mortality and cost implications. Transplant Proc 2001; 33: 1787-88.

5. Malhotra KK, Dash SC, Dhawan IK. Tuberculosis and renal transplantationobservations from an endemic area of tuberculosis. Post Grad Med J 1986; 62: 359- 62 . 